\title{
DAMPAK PERUBAHAN IKLIM TERHADAP PERILAKU DAN PENDAPATAN PETANI (The Impact of Climate Change to Farmers' Behavior and Revenue)
}

\author{
Elly Rasmikayati* dan Endah Djuwendah \\ Fakultas Pertanian, Universitas Padjadjaran, Jl. Raya Bandung-Sumedang Km 21, \\ Jatinangor, Sumedang 45363. \\ *Penulis korespondensi. Tel : 087822122143. Email: elly.agri@yahoo.co.id.
}

Diterima: 5 Desember 2014

Disetujui: 6 Juni 2015

\begin{abstract}
Abstrak
Pemanasan global selama abad terakhir telah mengakibatkan perubahan iklim yang sebagian besar terindikasi sebagai bencana lingkungan hidup seperti banjir, kekeringan dan bergesernya musim hujan. Bencana-bencana lingkungan hidup ini sangat berpengaruh terhadap sektor pertanian karena sektor ini memiliki ketergantungan tinggi pada kondisi iklim. Penelitian ini bertujuan untuk mengkaji dampak perubahan iklim terhadap perilaku mitigatif petani dan pendapatan petani. Penelitian dilakukan dengan metode survey-eksplanatory, dengan teknik pengambilan sampel multi-stage cluster random sampling. Hasil penelitian mengungkapkan bahwa dampak perubahan iklim terhadap perilaku mitigatif petani adalah bahwa secara umum perilaku petani padi sawah di Jawa Barat dan Jawa Timur telah cukup sesuai dengan perilaku yang mitigatif terhadap perubahan iklim seperti memperluas lahan, pemilihan sumber irigasi, memilih varietas unggul berorientasi iklim, pertimbangan iklim dalam memilih pupuk, perbaikan teknik usahatani, perubahan pola tanam serta menggeser masa tanam dan waktu panen. Sedangkan yang belum sesuai dengan perilaku yang mitigatif terhadap perubahan iklim adalah masih sedikitnya yang mengikuti sekolah iklim. Perilakuperilaku mitigatif yang telah dilakukan sebagian besar petani terhadap perubahan iklim menyebabkan produktivitas padi petani menjadi meningkat sehingga menyebabkan pendapatan petani di Jawa Barat dan Jawa Timur menjadi meningkat pula.
\end{abstract}

Kata kunci: perubahan iklim, perilaku mitigatif petani, pendapatan petani, padi sawah.

\begin{abstract}
Global warming over the past century has caused the climate change which mostly indicated as the environmental disasters such as floods, droughts and shifting rainy season. Environmental disasters are very influential on the agricultural sector because this sector has a high dependence on climatic conditions. This research aims to examine the impact of climate change on mitigative behavior of farmers and farmers' income. The research was conducted by Survey-explanatory method by using Multi Stage Cluster Random Sampling Techniques. Results revealed that the impact of climate change on farmer's mitigative behavior is that in general rice farmer's behavior in West Java and East Java have been quite in accordance with the behavior mitigative to climate change such expanding the field, selecting irrigation source, selecting climate-oriented varieties, climate considerations in choosing fertilizers, improved farming techniques, changes in cropping patterns and shifts the planting and harvest time. Meanwhile, the farmer's behavior that is not in accordance with the mitigative behavior to climate change are still at least that followed the climate school. Mitigative behaviors that have been done by the most of farmers to climate change led to the productivity of rice farmers be increased, causing farmers' income in West Java and East Java to be increased as well.
\end{abstract}

Keywords: climate change, mitigative behavior of farmers, farmers' income, mitigation, paddy.

\section{PENDAHULUAN}

Pemanasan global selama abad terakhir telah mengakibatkan perubahan iklim yang telah menjadi isu paling penting dalam kebijakan pembangunan dan global governance pada abad ke 21. Sebagian besar dari kejadian bencana tersebut merupakan bencana lingkungan hidup seperti angin puting beliung, banjir dan tanah longsor, yang sangat dipengaruhi oleh gejala perubahan iklim (Suharko, 2014).

Pemanasan global selama abad terakhir telah mengakibatkan perubahan iklim yang sangat berpengaruh terhadap sektor pertanian karena sektor ini memiliki ketergantungan tinggi pada kondisi iklim. Negara-negara sedang berkembang lebih rentan terhadap dampak perubahan iklim dibanding negara-negara maju karena predominansi sektor pertanian tadah hujan, kelangkaan modal untuk melakukan langkah-langkah adaptasi, baseline iklim yang lebih hangat, serta ekspose yang lebih tinggi terhadap kejadian-kejadian ekstrim (Chapagain dkk., 2009; Mertz dkk., 2009).

Penelitian mutakhir tentang perubahan iklim telah mencatat bahwa perubahan iklim menunjukkan gejala yang mengindikasikan adanya ancaman terhadap keberlanjutan produksi pangan di Indonesia (Naylor dkk., 2007; Natawidjaja, 2008) 
dan di negara-negara lain seperti Cina (Wang, 2010; Li dkk., 2010), Amerika (Shen dkk., 2010), Afrika (Gommes, 1998) dan Eropa (Olesen dan Bindi, 2002). Dalam beberapa tahun terakhir ini pergeseran musim hujan menyebabkan pergeseran musim tanam dan panen komoditi pangan (padi, palawija dan sayuran). Banjir dan kekeringan menyebabkan gagal tanam, gagal panen, dan bahkan menyebabkan puso. Hal ini berimplikasi pada penurunan produksi dan pendapatan petani. Akibatnya, sebagai negara dengan penduduk terbanyak keempat di dunia dan salah satu produsen terbesar dan konsumen beras, Indonesia ditandai dengan populasi miskin pedesaan yang bergantung pada produksi padi untuk mata pencaharian mereka (Natawidjaja dkk, 2009).

Produksi padi nasional periode 2006-2010 menunjukkan adanya peningkatan yang cukup meyakinkan. Laju pertumbuhan produksi padi ratarata $5 \%$ per tahun dengan nilai produksi mencapai 66,5 juta ton pada tahun 2010. Begitu pula produktivitas padi meningkat dengan laju pertumbuhan rata-rata $2 \%$ per tahun sehingga mencapai angka 5,2 ton per hektar pada tahun 2010 (Anonim, 2010).

Namun demikian jika diperhatikan lebih seksama, laju pertumbuhan produksi padi pada 2009 hanya meningkat 1\% dan pada tahun 2010 justru mengalami penurunan dari tahun sebelumnya. Begitu pula laju pertumbuhan produktivitas padi mengalami penurunan sejak tahun 2009. Gejala penurunan ini mengindikasikan faktor yang menunjukkan gejala perubahan yang secara pelan tapi pasti berpeluang mengancam pembangunan pertanian yaitu perubahan iklim.

Permasalahan yang muncul adalah tentang perubahan perilaku mitigatif yang dialakukan petani sebagai dampak dari perubahan iklim dan bagaimana pula dampaknya terhadap pendapatan mereka. Di negara berkembang seperti Indonesia, kurangnya penelitian serta bukti-bukti kredibel tentang dampak perubahan iklim terhadap kehidupan masyarakat petani dan produksi pangan merupakan tantangan yang harus segera dijawab. Mengingat pengetahuan petani mengenai perubahan iklim masih sangat terbatas, oleh karena itu tujuan dari penelitian ini adalah untuk mengkaji dampak perubahan iklim terhadap perilaku petani dan mengkaji dampak perubahan iklim terhadap pendapatan petani.

\section{METODE PENELITIAN}

\section{Desain Penelitian}

Penelitian dilakukan dengan metode Surveyeksplanatory, dengan teknik pengambilan sampel multi-stage cluster random sampling. Lokasi yang dipilih adalah dua provinsi utama sentra padi di
Indonesia, yaitu Provinsi Jawa Timur dan Jawa Barat. Dari masing-masing provinsi dipilih 3 kabupaten secara random dengan pembobotan berdasarkan jumlah produksi. Kabupaten yang terpilih adalah Indramayu, Karawang dan Subang untuk Jawa Barat serta Lamongan, Tuban dan Bojonegoro untuk Jawa Timur.

Selanjutnya dari setiap kabupaten dipilih 3 kecamatan secara random dari kecamatan penghasil padi, 2 kecamatan dari list kecamatan yang produksi padinya tinggi dan 1 kecamatan dari kecamatan yang produksinya rendah. Dengan demikian dari proses tersebut akan diperoleh cakupan daerah penelitian yang meliputi 2 provinsi, 6 kabupaten dan 18 kecamatan. Cakupan dari daerah penelitian ini didesain untuk cukup mewakili keragaman dinamis kondisi wilayah sentra produksi utama padi di Indonesia.

\section{Sampel Petani Padi}

Sampel petani padi random dipilih dari sampling frame didasarkan pada listing populasi petani padi dari BPS yang diperbaharui setiap 10 tahun. BPS membagi wilayah berdasarkan blok sensus yang merupakan pembagian lebih kecil dari desa/kelurahan, setiap blok sensus terdiri dari 80120 keluarga. Untuk masing-masing lokasi kecamatan terpilih, sampel diambil secara random hingga total sampel adalah 600 petani, 300 petani dari Jawa Barat dan 300 petani dari Jawa Timur. Penarikan sampel tersebut menggunakan teknik sampling acak banyak tahap (muti-stage random sampling)

\section{Operasionalisasi Variabel}

Sesuai dengan tujuan penelitian, maka terdapat dua konsep utama yaitu dampak perubahan iklim terhadap perilaku petani dan dampak perubahan iklim terhadap pendapatan petani. Variabel-variabel penelitian dari konsep dampak perubahan iklim terhadap perilaku petani adalah jumlah petani yang mengikuti sekolah iklim, jenis pelatihan pertanian, luas lahan, sumber irigasi, jenis varietas padi, asal benih padi, jenis pupuk, pertimbangan iklim dalam memilih pupuk, perbaikan teknik berusahatani, pola tanam padi dan bulan menanam padi dan bulan memanen padi. Variabel-variabel penelitian dari konsep dampak perubahan iklim terhadap pendapatan petani adalah biaya tenaga kerja, tingkat modal usahatani, asal modal usahatani, biaya input, biaya panen, biaya sewa lahan, produksi padi, jumlah tanggungan keluarga, harga beli padi, biaya irigasi, luas lahan dan biaya pajak.

\section{Metode Analisis}

Data mengenai perilaku dan pendapatan petani dianalisis secara kuantitatif menggunakan perhitungan statistik. Alat yang digunakan untuk 
mempresentasikan data berupa berbagai tabel, cross-tabulasi, diagram dan grafik. Selain itu, digunakan pula ukuran gejala pusat dan dispersi untuk mengetahui perilaku data secara deskriptif. Selanjutnya, data dijelaskan secara kualitatif berdasarkan kesimpulan kuantitatif yang sudah didapatkan sebelumnya kemudian dipadukan dengan analisis kualitatif untuk merumuskan interpretasi yang menyeluruh.

\section{HASIL DAN PEMBAHASAN}

\section{Perilaku Petani dalam Menghadapi Perubahan Iklim Jumlah petani yang mengikuti pelatihan sekolah iklim}

Tabel 1 merupakan hasil analisis mengenai perilaku petani dalam hal mengikuti pelatihan sekolah iklim. Berdasarkan Tabel 1 terlihat bahwa sangat sedikit petani yang mengikuti pelatihan sekolah iklim bahkan petani di Jawa Timur tidak ada satu pun yang mengikutinya. Pelatihan sekolah iklim yang tidak banyak diikuti petani disebabkan karena program tersebut belum secara intensif dilakukan oleh lembaga yang menyelenggarakannya bahkan di kebanyakan daerah belum terbentuk program sekolah iklim.

\section{Perubahan luas lahan}

Hal yang menarik terjadi pada perilaku petani dalam menambah luas lahan mereka. Pada tahun 1999, rata-rata luas lahan petani Jawa Barat (2,12 ha) lebih luas dari pada petani Jawa Timur $(0,84)$. Terjadi kenaikan luas lahan baik pada petani Jawa Barat maupun petani Jawa Timur pada tahun 2009. Rata-rata luas lahan petani Jawa Barat naik menjadi 3,10 ha pada tahun 2009 dan petani Jawa Timur

Tabel 1. Perilaku petani dalam hal mengikuti pelatihan sekolah iklim.

\begin{tabular}{lrrrr}
\hline \multirow{2}{*}{ Sekolah Iklim } & \multicolumn{2}{c}{ Jawa Barat } & \multicolumn{2}{c}{ Jawa Timur } \\
\cline { 2 - 5 } & Jumlah & \multicolumn{1}{c}{$\%$} & Jumlah & \multicolumn{1}{c}{$\%$} \\
\hline Mengikuti & 6 & 2 & - & - \\
Tidak & 292 & 98 & 300 & 100 \\
\hline Total & 300 & 100 & 300 & 100 \\
\hline
\end{tabular}

Sumber : Data primer, diolah. naik menjadi 1,08 ha pada tahun yang sama. Hal ini cukup bertentangan dengan teori dan hasil penelitian sebelumnya bahwa perubahan iklim akan mengurangi luas lahan petani. Setelah dianalisis ternyata perilaku petani untuk menambah luas lahan ini didorong oleh tindakan adaptasi untuk meminimalisasi risiko dari perubahan iklim terhadap penurunan produksi padi mereka.

\section{Sumber irigasi}

Perilaku yang lainnya dari petani yang cukup menarik adalah mengenai sumber irigasi yang mereka gunakan untuk mengairi lahan sawah mereka. Berdasarkan Tabel 2 terlihat pula bahwa persentase penggunaan bendungan oleh petani naik dalam 10 tahun terakhir. Hasil yang didapat adalah ternyata para petani telah banyak memanfaatkan bendungan sebagai sumber irigasi dari pada sumber air lainnya. Pemakaian bendungan sebagai sumber irigasi merupakan tindakan adaptasi yang baik dalam menghadapi perubahan iklim karena menurut petani bendungan di daerah mereka relatif stabil dalam kapasitas airnya bahkan pada saat kemarau sekalipun.

\section{Penggunaan jenis padi}

Sebagian besar petani Jawa Barat (75\%) dan petani Jawa Timur (82\%) menanam varietas unggul Ciherang. Penggunaan varietas ini juga terus meningkat dalam 10 tahun terakhir (Tabel 3). Perilaku ini sudah mendukung kegiatan mitigasi terhadap perubahan iklim. Hal ini sesuai dengan pendapat Susandi dkk. (2008) yang mengatakan bahwa penggunaan varietas ciherang yang berumur genjah dapat menekan emisi gas methan karena lama tumbuh tanaman juga mempengaruhi tingkat emisi $\mathrm{CH}_{4}$ dari lahan sawah, dimana semakin lama periode tumbuh tanaman semakin banyak eksudat dan biomassa akar yang terbentuk sehingga emisi $\mathrm{CH}_{4}$ semakin tinggi.

\section{Asal benih padi}

Perilaku petani dalam menghadapi perubahan iklim juga tercermin dalam memilih asal benih padi

Tabel 2. Perilaku petani dalam menggunakan sumber air untuk irigasi.

\begin{tabular}{lrrrrrr}
\hline \multirow{2}{*}{ Sumber air } & \multicolumn{3}{c}{ Jawa Barat (\%) } & \multicolumn{3}{c}{ Jawa Timur (\%) } \\
\cline { 2 - 7 } & 2009 & 2005 & 1999 & 2009 & 2005 & 1999 \\
\hline Tidak ada jawaban & 2,00 & 2,33 & 3,00 & 0,33 & 0,33 & 0,33 \\
Bendungan & 70,00 & 69,33 & 68,33 & 48,00 & 48,00 & 47,67 \\
Sungai & 14,00 & 14,00 & 13,67 & 50,67 & 50,67 & 51,33 \\
Sumur/pompa & 0,33 & 0,33 & 0,33 & 1,00 & 1,00 & 0,67 \\
Mata air & 11,67 & 11,67 & 11,67 & 0,00 & 0,00 & 0,00 \\
Embung & 2,00 & 2,33 & 3,00 & 0,00 & 0,00 & 0,00 \\
Lainnya, & 2,00 & 2,33 & 3,00 & 0,33 & 0,33 & 0,33 \\
\hline Total & 100 & 100 & 100 & 100 & 100 & 100 \\
\hline
\end{tabular}

Sumber : Data primer, diolah. 
Tabel 3. Perilaku petani dalam memilih varietas padi.

\begin{tabular}{lrrrrrr}
\hline \multirow{2}{*}{ Varietas padi } & \multicolumn{3}{c}{ Jawa Barat (\%) } & \multicolumn{3}{c}{ Jawa Timur (\%) } \\
\cline { 2 - 7 } & 2009 & 2005 & 1999 & 2009 & 2005 & 1999 \\
\hline Tidak ada jawaban & 0,00 & 1,33 & 2,00 & 1,33 & 3,00 & 3,33 \\
Ciherang & 75,00 & 66,33 & 42,00 & 82,33 & 66,67 & 26,00 \\
Hibrida & 1,33 & 2,67 & 5,67 & 1,33 & 1,00 & 1,67 \\
IR 64 & 5,00 & 10,33 & 22,33 & 14,00 & 21,67 & 54,33 \\
Membramo & 0,00 & 0,00 & 0,00 & 0,00 & 0,00 & 0,33 \\
Ketan & 9,67 & 10,33 & 6,00 & 0,00 & 0,00 & 0,00 \\
Lainnya & 9,00 & 9,00 & 22,00 & 1,00 & 7,67 & 14,33 \\
\hline Total & 100 & 100 & 100 & 100 & 100 & 100 \\
\hline
\end{tabular}

Sumber : Data primer, diolah.

Tabel 4. Asal benih padi.

\begin{tabular}{lrrrrrr}
\hline \multirow{2}{*}{ Asal benih padi } & \multicolumn{3}{c}{ Jawa Barat (\%) } & \multicolumn{3}{c}{ Jawa Timur (\%) } \\
\cline { 2 - 7 } & 2009 & 2005 & 1999 & 2009 & 2005 & 1999 \\
\hline Tidak ada jawaban & 0,00 & 1,33 & 2,00 & 0,33 & 2,00 & 2,33 \\
BBU/BBI & 4,33 & 4,33 & 4,33 & 18,00 & 17,67 & 18,33 \\
Penangkar & 0,33 & 1,00 & 1,00 & 0,67 & 0,67 & 1,00 \\
Petani lain & 14,67 & 14,00 & 12,67 & 9,00 & 9,67 & 11,00 \\
Produksi sendiri & 14,67 & 13,00 & 11,33 & 7,67 & 8,67 & 8,67 \\
Toko Saprodi & 63,33 & 63,67 & 66,67 & 42,33 & 40,00 & 40,00 \\
Lainnya & 2,67 & 2,67 & 2,00 & 19,33 & 18,67 & 18,67 \\
Petani lain dan toko saprodi & 0,00 & 0,00 & 0,00 & 0,33 & 0,33 & 0,00 \\
Hail produksi dan toko lain & 0,00 & 0,00 & 0,00 & 2,33 & 2,33 & 0,00 \\
\hline Total & 100 & 100 & 100 & 100 & 100 & 100 \\
\hline
\end{tabular}

Sumber : Data primer, diolah.

Tabel 5. Pertimbangan iklim dalam memilih pupuk.

\begin{tabular}{lrrrrrr}
\hline \multicolumn{1}{c}{$\begin{array}{c}\text { Pertimbangan iklim dalam } \\
\text { memilih pupuk }\end{array}$} & \multicolumn{3}{c}{ Jawa Barat (\%) } & \multicolumn{3}{c}{ Jawa Timur (\%) } \\
\cline { 2 - 7 } & 2009 & 2005 & 1999 & 2009 & 2005 & 1999 \\
\hline 0. Tidak ada jawaban & 0,3 & 2,0 & 6,3 & - & 2,3 & 6,0 \\
1. Ya & 66,0 & 61,3 & 49,0 & 51,3 & 48,3 & 44,3 \\
2. Tidak & 33,7 & 36,7 & 44,7 & 48,7 & 49,3 & 49,7 \\
\hline Total & 100 & 100 & 100 & 100 & 100 & 100 \\
\hline
\end{tabular}

Sumber : Data primer, diolah.

Tabel 6. Perubahan teknik karena perubahan iklim.

\begin{tabular}{lcrrr}
\hline \multirow{2}{*}{ Perubahan teknik berusaha tani } & Jawa Barat & \multicolumn{2}{c}{ Jawa Timur } \\
\cline { 2 - 5 } & Jumlah responden & $\%$ & Jumlah responden & $\%$ \\
\hline Tidak ada jawaban & 6 & 2,0 & 2 & 0,7 \\
Ya & 162 & 54,0 & 214 & 71,3 \\
Tidak & 132 & 44,0 & 84 & 28,0 \\
\hline Total & 300 & 100 & 300 & 100 \\
\hline
\end{tabular}

Sumber : Data primer, diolah.

yang akan mereka tanam. Toko Saprodi adalah yang paling banyak dipilih petani baik petani Jawa Barat maupun Jawa Timur walaupun petani Jawa Barat yang memilih toko saprodi lebih banyak dari pada petani Jawa Timur (Tabel 4). Hal ini juga sudah merupakan upaya mitigatif petani terhadap perubahan iklim karena biasanya benih yang berasal dari toko saprodi sudah tersertifikasi dan memiliki kualitas yang baik dalam hal produktivitas.

\section{Pertimbangan iklim dalam penggunaan pupuk}

Berdasarkan Tabel 5, terlihat bahwa terjadi tren peningkatan kesadaran petani untuk mempertimbangkan faktor iklim dalam memilih pupuk. Perilaku mitigatif dalam penggunaan pupuk menggambarkan bahwa sudah banyak petani yang menggunakan pupuk organik dan mengurangi penggunaan pupuk urea. Menurut hasil penelitian Anomin (2004), penggunaan pupuk urea per ton berpotensi menghasilkan laju emisi $\mathrm{NO}_{2}$ sebesar 0,20 ton/tahun.

\section{Teknik berusahatani}

Berdasarkan Tabel 6, petani Jawa Timur (71,3\%) dan Jawa Barat (54\%) mengaku bahwa perubahan iklim telah menyebabkan perubahan perilaku mereka dalam hal teknik berusahatani. Petani Jawa Timur lebih banyak yang melakukan perubahan teknik usahatani dari pada Petani Jawa Barat. Hal ini menggambarkan bahwa para petani telah beradaptasi dan melakukan tindakan mitigatif terhadap perubahan iklim. dalam hal teknik berusahatani menghadapi perubahan iklim. 


\section{Pola tanam padi}

Berdasarkan Tabel 7, kebanyakan petani Jawa Barat menggunakan pola tanam padi-padi-bera dengan persentase sebesar 67,7\% pada tahun 1999 dan terus meningkat hingga pada tahun 2009 sebesar 71,7\%. Sedangkan kebanyakan petani Jawa Timur, persentase jumlah petani Jawa Timur yang menggunakan pola tanam padi-padi-palawija sebesar 45,3\% pada tahun 1999 dan terus meningkat hingga pada tahun 2009 sebesar 48,3\%. Mengingat pola tanam padi-padi-bera adalah pola tanam yang mitigatif terhadap perubahan iklim, maka petani Jawa Barat lebih mitigatif dari pada petani Jawa Timur.

\section{Bulan menanam dan memanen padi}

Dalam menghadapi perubahan iklim terutama perubahan musim hujan dan kemarau, dapat merubah perilaku petani dalam memulai tanam padi dan memanen hasil padi mereka. Berdasarkan Tabel 8 dapat disimpulkan bahwa telah terjadi perubahan masa tanam musim rendeng (hujan) petani jawa barat. Tahun 1999 penanaman terbanyak pada bulan November dan Januari kemudian tahun 2005 bergeser menjadi bulan November dan Desember dan tahun 2009 bergeser menjadi bulan Januari, Februari, dan Maret. Perubahan masa tanam musim rendeng (hujan) petani jawa timur juga terjadi, Tahun 1999, 2005 dan 2009,penanaman terbanyak pada bulan Oktober

Tabel 7. Pola tanaman padi.

\begin{tabular}{lrrrrrr}
\hline \multirow{2}{*}{ Pola tanam } & \multicolumn{3}{c}{ Jawa Barat (\%) } & \multicolumn{3}{c}{ Jawa Timur (\%) } \\
\cline { 2 - 7 } & 2009 & 2005 & 1999 & 2009 & 2005 & 1999 \\
\hline Tidak ada jawaban & 0,0 & 1,3 & 1,3 & 0,3 & 0,7 & 1,3 \\
Padi-padi-padi & 12,3 & 12,3 & 11,7 & 29,0 & 29,3 & 28,0 \\
Padi-padi-pala & 2,3 & 2,0 & 1,7 & 48,3 & 47,7 & 45,3 \\
Padi-padi-bera & 71,7 & 70,0 & 67,7 & 16,3 & 16,0 & 16,0 \\
Lainnya & 13,7 & 14,3 & 17,7 & 6,0 & 6,3 & 9,3 \\
\hline Total & 100 & 100 & 100 & 100 & 100 & 100 \\
\hline
\end{tabular}

Sumber : Data primer, diolah.

Tabel 8. Bulan aktivitas menanam rendeng.

\begin{tabular}{|c|c|c|c|c|c|c|}
\hline \multirow{2}{*}{$\begin{array}{l}\text { Rendeng (penanaman dan } \\
\text { pemanenan) } \\
\text { Penanaman }\end{array}$} & \multicolumn{3}{|c|}{ Jawa Barat (\%) } & \multicolumn{3}{|c|}{ Jawa Timur (\%) } \\
\hline & 2009 & 2005 & 1999 & 2009 & 2005 & 1999 \\
\hline Tidak ada jawaban & 0,0 & 1,3 & 1,7 & 0,3 & 2,0 & 2,7 \\
\hline Januari & 17,7 & 10,0 & 31,7 & 0,3 & 0,3 & 0,3 \\
\hline Februari & 25,0 & 10,7 & 12,0 & 0,0 & 0,0 & 0,0 \\
\hline Maret & 18,0 & 12,0 & 6,0 & 0,0 & 0,0 & 0,0 \\
\hline April & 0,7 & 1,3 & 0,7 & 0,0 & 0,0 & 0,0 \\
\hline Mei & 0,3 & 0,7 & 0,3 & 0,0 & 0,0 & 0,0 \\
\hline Juni & 0,0 & 0,0 & 0,0 & 15,7 & 0,7 & 1,0 \\
\hline Juli & 1,0 & 1,0 & 2,0 & 2,0 & 15,0 & 14,7 \\
\hline Agustus & 0,0 & 0,0 & 0,0 & 14,3 & 2,0 & 2,0 \\
\hline September & 0,0 & 0,0 & 0,0 & 34,0 & 13,0 & 13,0 \\
\hline Oktober & 1,3 & 2,0 & 1,7 & 27,0 & 33,7 & 34,0 \\
\hline Nopember & 16,7 & 31,3 & 31,3 & 6,3 & 22,3 & 21,7 \\
\hline Desember & 19,3 & 29,7 & 12,7 & 2,0 & 11,0 & 10,7 \\
\hline Total & 100 & 100 & 100 & 100 & 100 & 100 \\
\hline \multicolumn{7}{|l|}{ Pemanenan } \\
\hline Tidak ada jawaban & 0,0 & 1,3 & 1,7 & 26,7 & 2,0 & 2,7 \\
\hline Januari & 0,7 & 0,3 & 0,3 & 33,3 & 24,0 & 23,7 \\
\hline Februari & 7,7 & 6,7 & 8,0 & 6,3 & 36,3 & 36,0 \\
\hline Maret & 18,3 & 31,3 & 32,0 & 0,3 & 6,7 & 6,7 \\
\hline April & 18,0 & 32,3 & 36,3 & 0,3 & 0,3 & 0,3 \\
\hline Mei & 26,7 & 4,0 & 5,7 & 0,0 & 0,0 & 0,0 \\
\hline Juni & 17,0 & 16,0 & 11,3 & 0,0 & 0,0 & 0,0 \\
\hline Juli & 10,0 & 5,7 & 2,0 & 0,0 & 0,0 & 0,0 \\
\hline Agustus & 0,7 & 1,3 & 0,3 & 16,0 & 0,0 & 0,0 \\
\hline September & 0,0 & 1,0 & 0,0 & 0,0 & 14,0 & 14,0 \\
\hline Oktober & 0,0 & 1,3 & 0,0 & 0,0 & 1,7 & 1,7 \\
\hline Nopember & 1,0 & 0,3 & 2,3 & 5,7 & 5,7 & 5,7 \\
\hline Desember & 0,0 & 0,0 & 0,0 & 11,3 & 9,3 & 9,3 \\
\hline Total & 100 & 100 & 100 & 100 & 100 & 100 \\
\hline
\end{tabular}

Sumber : Data primer, diolah. 
dan November. Kemudian terjadi pergeseran masa tanam dari bulan Juli (2005) ke Juni (2009).

Pada musim gadu (kemarau) seperti tersaji pada Tabel 9, perubahan masa tanam musim gadu (kering) petani jawa barat ditandai dengan kenaikan persentase jumlah petani yang melakukan masa tanam pada bulan Mei sampai Agustus, kemudian, jerjadi penurunan tajam persentase jumlah petani yang menanam pada bulan April 2009 dalam selang 10 tahun. Perubahan masa tanam musim gadu (kering) petani jawa timur terlihat bahwa dari Tahun 1999, 2005 dan 2009, penanaman biasanya dilakukan pada bulan Maret sampai Juni namun terjadi pergeseran masa tanam dari bulan Desember (2005) ke Oktober (2009).

\section{Pendapatan Petani Jawa Barat dan Jawa Timur Terkait Perubahan Iklim}

Seperti tersaji pada Tabel 10, kebanyakan petani baik di Jawa Barat maupun Jawa Timur adalah petani yang mempunyai pendapatan per bulan di bawah 2 juta rupiah (lebih dari 60\%). Yang menarik adalah bahwa persentase petani yang berpendapatan kurang dari 1 juta per bulan menurun dalam 10 tahun terakhir sedangkan yang berpenghasilan antara 1 juta sampai 2 juta meningkat. Hal ini disebabkan karena peningkatan dalam hal produktivitas padi petani (Tabel 11).

Secara teori, perubahan iklim berisiko menurunkan pendapatan petani, namun ternyata perilaku-perilaku mitigatif petani terhadap peru-

Tabel 9. Bulan aktivitas menanam gadu.

\begin{tabular}{|c|c|c|c|c|c|c|}
\hline Gadu & \multicolumn{3}{|c|}{ Jawa Barat (\%) } & \multicolumn{3}{|c|}{ Jawa Timur (\%) } \\
\hline Penanaman & 2009 & 2005 & 1999 & 2009 & 2005 & 1999 \\
\hline Tidak ada jawaban & 0,0 & 1,3 & 1,7 & 0,3 & 2,0 & 2,7 \\
\hline Januari & 0,0 & 1,0 & 4,3 & 0,0 & 0,0 & 0,0 \\
\hline Februari & 1,0 & 1,0 & 0,0 & 0,0 & 0,7 & 0,7 \\
\hline Maret & 0,0 & 20,3 & 0,0 & 20,7 & 13,7 & 11,0 \\
\hline April & 7,3 & 28,0 & 20,7 & 12,7 & 18,7 & 21,3 \\
\hline Mei & 31,0 & 8,7 & 27,7 & 26,0 & 24,7 & 9,0 \\
\hline Juni & 13,3 & 27,3 & 10,7 & 21,7 & 21,3 & 36,0 \\
\hline Juli & 29,7 & 10,3 & 23,7 & 3,0 & 3,3 & 3,7 \\
\hline Agustus & 15,0 & 2,0 & 9,3 & 0,0 & 0,0 & 0,0 \\
\hline September & 2,7 & 0,0 & 2,0 & 0,0 & 0,0 & 0,0 \\
\hline Oktober & 0,0 & 0,0 & 0,0 & 15,7 & 0,0 & 0,0 \\
\hline Nopember & 0,0 & 0,0 & 0,0 & 0,0 & 0,0 & 0,0 \\
\hline Desember & 0,0 & 1,3 & 0,0 & 0,0 & 15,7 & 15,7 \\
\hline Total & 100 & 100 & 100 & 100 & 100 & 100 \\
\hline \multicolumn{7}{|l|}{ Pemanenan } \\
\hline Tidak ada jawaban & 0,0 & 0,0 & 1,7 & 0,3 & 2,0 & 2,7 \\
\hline Januari & 0,0 & 1,3 & 2,3 & 0,0 & 0,0 & 0,0 \\
\hline Februari & 1,7 & 2,0 & 0,0 & 0,0 & 15,7 & 15,7 \\
\hline Maret & 0,3 & 0,0 & 0,0 & 0,0 & 0,0 & 0,0 \\
\hline April & 0,0 & 0,0 & 0,0 & 0,0 & 0,0 & 0,0 \\
\hline Mei & 0,0 & 1,0 & 4,3 & 0,0 & 0,7 & 0,7 \\
\hline Juni & 1,0 & 4,7 & 0,7 & 20,7 & 13,7 & 11,7 \\
\hline Juli & 0,3 & 5,0 & 8,7 & 5,3 & 11,3 & 13,7 \\
\hline Agustus & 7,3 & 23,3 & 24,7 & 4,3 & 3,7 & 3,7 \\
\hline September & 24,7 & 16,0 & 18,3 & 50,3 & 50,0 & 49,0 \\
\hline Oktober & 1,3 & 15,7 & 9,7 & 3,3 & 3,0 & 3,0 \\
\hline Nopember & 31,3 & 23,7 & 23,7 & 0,0 & 0,0 & 0,0 \\
\hline Desember & 21,7 & 7,3 & 6,0 & 15,7 & 0,0 & 0,0 \\
\hline Total & 100 & 100 & 100 & 100 & 100 & 100 \\
\hline
\end{tabular}

Sumber : Data primer, diolah.

Tabel 10. Pendapatan keluarga.

\begin{tabular}{lrrrrrr}
\hline Kategori pedapatan keluarga & \multicolumn{3}{c}{ Jawa Barat (\%) } & \multicolumn{3}{c}{ Jawa Timur (\%) } \\
\cline { 2 - 7 } \multicolumn{1}{c}{ per bulan } & 2009 & 2005 & 1999 & 2009 & 2005 & 1999 \\
\hline Tidak ada jawaban & 0,00 & 0,33 & 0,33 & 0,00 & 1,33 & 2,00 \\
$<999.000$ & 36,33 & 50,67 & 57,33 & 33,00 & 49,67 & 62,33 \\
$1.000 .000-1.999 .999$ & 33,67 & 25,00 & 21,67 & 35,67 & 32,67 & 24,67 \\
$2.000 .000-2.999 .999$ & 11,33 & 8,33 & 8,67 & 17,00 & 9,33 & 5,00 \\
$3.000 .000-3.999 .999$ & 6,00 & 5,33 & 5,33 & 8,33 & 1,33 & 1,33 \\
$>4.000 .000$ & 12,67 & 10,33 & 6,67 & 6,00 & 5,67 & 4,67 \\
\hline Total & 100 & 100 & 100 & 100 & 100 & 100 \\
\hline
\end{tabular}

Sumber : Data primer, diolah. 
Tabel 11. Perubahan produktivitas tanaman padi di Jawa Barat dan Jawa Timur.

\begin{tabular}{|c|c|c|c|c|c|c|}
\hline $\begin{array}{c}\text { Perubahan produktivitas } \\
\text { tanaman padi }\end{array}$ & $\begin{array}{c}2009 \\
(\%)\end{array}$ & $\begin{array}{c}2005 \\
(\%) \\
\end{array}$ & $\begin{array}{l}1999 \\
(\%)\end{array}$ & $\begin{array}{c}2009 \\
(\%)\end{array}$ & $\begin{array}{c}2005 \\
(\%)\end{array}$ & $\begin{array}{c}1999 \\
(\%)\end{array}$ \\
\hline Tidak ada jawaban & 0,0 & 1,7 & 2,0 & 0,0 & 1,7 & 2,3 \\
\hline $\mathrm{Ya}$ & 73,3 & 62,0 & 60,3 & 71,3 & 50,0 & 46,3 \\
\hline Tidak & 26,7 & 36,3 & 37,7 & 28,7 & 48,3 & 51,3 \\
\hline Total & 100 & 100 & 100 & 100 & 100 & 100 \\
\hline
\end{tabular}

bahan iklim seperti yang telah dibahas pada sub bab sebelumnya menyebabkan produktivitas padi petani menjadi meningkat sehingga menyebabkan pedapatan petani di Jawa Barat dan Jawa Timur menjadi meningkat pula.

Saran Kebijakan yang Dapat Mendukung Petani Kecil dan Keluarga Miskin di Pedesaan terhadap Perubahan Iklim

Peran pemerintah sangat diperlukan terutama dalam pengembangan dan percepatan adopsi teknologi usahatani yang lebih produktif dan adaptif terhadap perubahan iklim, penyediaan infrastruktur pertanian yang efektif untuk mendukung aplikasi teknologi tersebut, pengembangan jaringan informasi iklim pertanian, pengembangan kelembagaan perlindungan petani terhadap dampak negatif iklim ekstrim pada usahatani, dan kebijakan harga masukan dan keluaran usahatani yang kondusif untuk pendapatan petani.

Kebijakan dan strategi peningkatan kapasitas adaptasi petani harus berbasis penguatan sinergi antara adaptasi yang secara historis telah dikembangkan mandiri oleh petani dengan adaptasi terencana yang diintroduksikan oleh pemerintah. Untuk meningkatkan kapasitas adaptasi petani terhadap perubahan iklim maka aksi adaptasi terhadap perubahan iklim harus diposisikan sebagai bagian integral program pembangunan pertanian, terutama pada subsektor pangan. Mengingat bahwa keberhasilan aksi adaptasi terletak pada partisipasi semua pihak yang berkepentingan maka hal mainstreaming adaptasi terhadap perubahan iklim dalam kebijakan subsektor pangan perlu dilakukan di semua level.

\section{KESIMPULAN}

Dampak perubahan iklim terhadap perilaku petani adalah bahwa secara umum perilaku petani padi sawah di Jawa Barat dan Jawa Timur telah cukup sesuai dengan perilaku yang mitigatif terhadap perubahan iklim seperti memperluas lahan, pemilihan sumber irigasi, memilih varietas unggul berorientasi iklim, pertimbangan iklim dalam memilih pupuk, perbaikan teknik usahatani, perubahan pola tanam serta menggeser masa tanam dan waktu panen. Untuk perilaku yang belum sesuai dengan perilaku yang mitigatif terhadap perubahan iklim adalah masih sedikitnya yang mengikuti sekolah iklim. Perubahan iklim berisiko menurunkan pendapatan petani, namun perilakuperilaku mitigatif yang telah dilakukan petani terhadap perubahan iklim menyebabkan produktivitas padi petani menjadi meningkat sehingga menyebabkan pedapatan petani di Jawa Barat dan Jawa Timur menjadi meningkat pula.

\section{DAFTAR PUSTAKA}

Anomin, 2010. Jawa Barat dalam Angka. Badan Pusat Statistik, Provinsi Jawa Barat. Bandung.

Chapagain, B.K., Subedi, R., dan Paudel, N.S., 2009. Exploring Local Knowledge of Climate Change: Some Reflections. Journal of Forest and Livelihood. 8:108-112.

Gommes, R., 1998. Some Aspects of Climate Variability and Food Security in Sub-Saharan Africa. Royal Meteorological Institute and Royal Academy of Overseas Science, Brussels.

Li, C., Ting, Z., dan Rasaily, R.G., 2010. Farmer's Adaptation to Climate Risk in the Context of China: A Research on Jianghan Plain of Yangtze River Basin. Agriculture and Agricultural Science Procedia. 1:116-125.

Mertz, H., Howden, S.M., Struik, P.C., Nelson, R., Rodriguez, D., dan Chapman S.C., 2009. Adaptation Science for Agricultural and Natural Resource Management - Urgency and Theoretical Basis. Current Opinion in Environment Sustainability. 1:69-76.

Natawidjaja, R.S., Supyandi, D., Tulloh, C., Tridakusumah, A.C., Calford, E.M., dan Ford, M., 2009. Climate Change, Food Security and Income Distribution: Adaptations of Small Rice Farmers. Crawford School of Economics and Government at The Australian National University, Canberra.

Naylor, R.L., Battisti, D.S., Vimont, D.J., Falcon, W.P., dan Burke, M.B., 2007. Assessing Risks of Climate Variability and Climate Change for Indonesian Rice Agriculture. Proceedings of the National Academy of Sciences of the United States of America. 104(19):7752-7757.

Olesen, J.E,. dan Bindi, M., 2002. Consequences of Climate Change for European Agricultural 
Productivity, Land Use and Policy. European Journal of Agronomy. 16:239-262.

Shen, S., Basist. A., dan Howard, A., 2010. Structure of A Digital Agriculture System and Agricultural Risks due to Climate Changes. Agriculture and Agricultural Science Procedia 1:42-51.

Suharko., 2009. Pencegahan Bencana Lingkungan Hidup Melalui Pendidikan Lingkungan. Jurnal Manusia dan Lingkungan, 21(2):254-260.
Susandi, A., Tamamadin, M., dan Nurlela, I. 2008. Fenomena Perubahan Iklim dan Dampaknya Terhadap Ketahanan Pangan di Indonesia. Prosiding Seminar Nasional Padi. 1:73-79.

Wang, J., 2010. Food Security, Food Prices and Climate Change in China: a Dynamic Panel Data Analysis. Agriculture and Agricultural Science Procedia 1:321-324. 